Original Research

\title{
Determining Near Point of Convergence: Exploring a Component of the Vestibular/Ocular Motor Screen Comparing Varied Target Sizes
}

John D Heick, PT, PhD, DPT, OCS, NCS, SCS ${ }^{1}$, Curt Bay, PhD ${ }^{2}$

1 Department of Physical Therapy and Athletic Training, Northern Arizona University, ${ }^{2}$ Department of Interdisciplinary Health Sciences, A.T. Still University

Keywords: movement system, oculomotor, concussion assessment

https://doi.org/10.26603/001c.18867

\section{International Journal of Sports Physical Therapy}

Vol. 16, Issue 1, 2021

\section{Background}

Near point of convergence (NPC), a component of the Vestibular Ocular Motor Screening (VOMS) assessment, may be helpful in diagnosing concussion. The VOMS uses a standardized approach to measure NPC; however, methods of screening for NPC are not standardized.

\section{Purpose}

The purpose of this study was to determine whether four different methods of measuring NPC yielded different estimates.

\section{Study Design}

Descriptive within-subjects laboratory study.

\section{Level of Evidence}

Level 3.

\section{Methods}

Healthy recreational athletes participated in a comparison of 4 commonly used methods of measuring NPC: a 12-point font target, the VOMS (14-point font target), the tip of a black pen, and the Bernell Vergel ${ }^{\mathrm{TM}}$ device (9-point font target). The order of the presentation of the 4 targets was randomized.

\section{Results}

Seventy-five participants (59 females, 16 males; mean [SD] age $=21.0$ [6.12] years) completed 3 trials. The mean (SD) of the 900 NPC measurements was $7.11(3.67) \mathrm{cm}$. Measurements for all targets had excellent reliability ( $r=0.94$ to 0.98$)$. In a comparative analysis, participant age was associated with NPC $(p<0.01)$ and was covaried. The NPCs derived from both the 12-point and 14-point font targets were smaller than NPCs from the tip of the black pen and the 9-point font device $(p<0.01)$. Measurements between the tip of the black pen and the 9-point font device $(p=0.25)$ and between the 12-point and 14 -point font targets $(p=0.84)$ did not differ.

\section{Conclusions}

The method used to measure NPC as a screening test for concussion should be standardized because the estimate differs depending on the technique chosen. The current study supports previous findings that the type of target used to measure NPC should be standardized for concussion assessment.

Corresponding author:

John D. Heick, PT, PhD, DPT

Northern Arizona University, PO Box 15105

Flagstaff, Arizona 86011, USA

Telephone: 928-523-8394, fax: 928-523-9289

e-mail: John.Heick@nau.edu 


\section{Clinical Relevance}

Screening of NPC should be standardized for concussion assessment to improve the reliability of NPC testing.

\section{INTRODUCTION}

Considering that 1.6 to 3.8 million sport- and recreationrelated concussions occur annually in the US, and the potential exists for cumulative effects after repeated injuries, sport-related concussion is a public health issue. ${ }^{1}$ Further, concussions are one of the most prevalent acquired neurologic conditions in young adults, and disruption to the brain commonly manifests as various deficits in the following three global categories:1,2 physical symptoms, cognition, and postural stability. A multifaceted concussion assessment approach must address all three categories because concussion deficits manifest differently in different patients. ${ }^{3,4}$ Vision, one outcome tested for postural stability, uses almost half the pathways in the brain; these anatomical structures are susceptible to injury in a concussed athlete. ${ }^{4}$ Visual-motor disruptions include difficulty with saccades, accommodation, smooth pursuit, and fixation. ${ }^{4,5}$ An estimated $65 \%-90 \%$ of concussed patients have oculomotor disruptions, 3,6 such as convergence insufficiency, slowed saccadic function, and smooth pursuit deficits. ${ }^{4}$

Oculomotor assessment is often used by healthcare professionals to evaluate visual-motor disruptions after a suspected concussion. The Vestibular Ocular Motor Screening (VOMS) assessment, which combines oculomotor and vestibular tests with a concussion symptom scale, has been shown to be useful in identifying concussions. ${ }^{7}$ Posttraumatic vision or oculomotor dysfunctions are reported in $30 \%-65 \%$ of concussed patients. ${ }^{8}$ Abnormal near point of convergence (NPC), one type of oculomotor dysfunction, is estimated to occur in $46 \%$ of athletes after concussion. $7,9-13$ Convergence occurs when a target is moved toward a patient's eyes and the eyes converge or move toward the target. The target doubles or presents as diplopia as it approaches the eye. Abnormal NPC has been defined as being unable to see a target clearly at a distance of more than 5 $\mathrm{cm}$ from the eye and represents the threshold for NPC. ${ }^{7} \mathrm{~Pa}-$ tients with convergence insufficiency commonly experience diplopia, blurred vision, headaches, or dizziness and nausea. 14

Near point convergence is a component of the VOMS assessment, and several studies investigating the VOMS reported an abnormal NPC was associated with prolonged concussion symptoms. ${ }^{15-17}$ Although the VOMS uses a standardized approach to measure NPC, different methods of measuring NPC are commonly used. The literature regarding the use of the VOMS instructs clinicians to use a 14-point font size letter on the end of a tongue depressor to measure NPC. ${ }^{7}$ The 14 -point font size target is moved by the patient from arm's length toward the tip of the nose, and the examiner uses a ruler to determine the NPC. ${ }^{7}$ This method includes subjective and objective approaches to determine NPC; patients are instructed to stop moving the target when they observe two distinct images (diplopia) or when the examiner observes an outward deviation of one eye. Three trials requiring about 30 seconds are performed, and the NPC measurements are averaged to yield an estimate.

Some have proposed measuring NPC with other devices independently of the VOMS. Further, the method of measuring NPC tends to differ across disciplines. For example, Pearce et al. ${ }^{13}$ used a standard Gulick tape measure that patients moved from arm's length to the tip of their nose. The NPC of 78 concussed athletes aged 9-24 years was measured, and a 12-point font size letter was used as the target. ${ }^{13}$ The authors correlated NPC measurements with cognitive impairment evaluated by the Immediate Post-Concussion and Cognitive Test (ImPACT) using a standard of more than $5 \mathrm{~cm}$ to indicate an abnormal NPC. ${ }^{13}$ The athletes repeated three consecutive trials without rest, and the intraclass correlation coefficients (ICCs) across the three trials ranged from 0.95 to $0.98 .{ }^{13}$ Athletes with impaired convergence performed worse on the ImPACT for the verbal memory, visual motor speed, and reaction time tests; they also reported higher total symptom scores. ${ }^{13}$ Further, $42 \%$ of these athletes had impaired convergence one month after their concussion. ${ }^{13}$ As with the VOMS assessment, the NPC for this study was determined when the patient saw two distinct images or when the examiner observed outward deviation of one eye.

In another study, Adler et al. ${ }^{18}$ investigated NPC using 4 different target sizes, including the tip of a pencil, and found that NPC was significantly different for different target types. The authors used the tip of a pencil because it is a more precise target than a 12-point or 14-point font size letter. ${ }^{18}$ The authors also controlled for the speed of the target's approach by moving it toward the tip of the nose at a rate of approximately $1-2 \mathrm{~cm} / \mathrm{s} .{ }^{18}$

While these traditional VOMS measures are taken with readily available inexpensive items, there are devices available that specifically measure convergence. The Bernell Vergel $^{\text {TM }}$ (Mishawaka, IN) is a battery-operated device that measures convergence by using a 9-point font size target for evaluation. To the authors' knowledge, the Bernell Vergel has not been investigated rigorously as a test for NPC.

Multiple disciplines are investigating NPC because of its relationship with concussions. Using evidence-based assessment tools such as the VOMS requires a systematic approach. Since multiple disciplines use multiple methods to measure NPC and precision is needed for concussion assessment, it would be helpful for clinicians to use a standardized approach. Therefore, the purpose of the current study was to determine whether four different NPC measurement methods of measuring NPC yielded different estimates.

\section{METHODS}

The current study used a prospective within-subjects research design to compare 4 standardized, commonly used methods of measuring NPC: a 12-point font target, the 
VOMS (14-point font target), the tip of a black pen, and the Bernell Vergel device (9-point font target). The study was conducted from February to December 2018. All experimental procedures were approved by the Northern Arizona University Institutional Review \#1195714-1.

\section{PARTICIPANTS}

Potential participants were healthy recreational athletes recruited through flyers distributed at a university campus. Participants had to be aged 18-50 years and proficient in speaking and reading English so they could understand directions for testing. Potential participants were excluded if they had a history of head, neck, or face injury in the past year or had any diagnosed neurological or ocular disorder. Participants meeting inclusion criteria were provided information about the nature of the study and completed written informed consent.

\section{PROCEDURES}

All testing was conducted at a university research laboratory and was administered by the same researcher. All measurements were collected during a single testing session. Participants who wore glasses or contacts were informed that they could use them if they wished. Instructions were provided before each of the four tests, and participants were offered short rest breaks, as needed, for no more than one minute during testing. To control for order effect of the four tests, the order in which the tests were presented was randomized before each session using a random number generator. All tests were completed in a seated position and at the same location in the laboratory because it provided adequate lighting. Three trials of each test were performed. Distances for NPC were measured using a standard ruler for all tests except the one using the Bernell Vergel device, which does not require a ruler.

\section{INSTRUMENTATION}

Instructions for the VOMS tool were modified based on a review of the literature and were consistently used for testing of all participants. The specific modifications included 1 : the size of the target; 2 . the examiner started the target at arm's length away from the participant and moved it toward the center of the participant's eyes at a rate of approximately $1-2 \mathrm{~cm} / \mathrm{s}$; and, 3 . the examiner was seated to the side of the participant to view the ruler and observe the participant's eyes. The NPC was established when participants indicated they saw two distinct images or when the examiner observed an outward deviation of one eye. Blurring of the image was ignored because it is a normal reaction.

For the tests with the 12-point and 14-point font targets, the target was an " $\mathrm{X}$ " printed in the required font size and placed on the end of a tongue depressor. For the test with the tip of a black pen, the target was the tip of a black BIC ${ }^{\circledR}$ (Shelton, CT) pen. The distance between the target and the tip of the participant's nose for these 3 tests was measured in centimeters with a standard ruler and recorded.

For the Bernell Vergel device test, the target was a 9-point font size "X" located on the Bernell Vergel device.
The examiner depressed a button on the device when the participant reported diplopia or the examiner observed outward deviation of one eye. The Bernell Vergel device uses an on-board microprocessor and ultrasonic technology to measure the distance from the participant to the target in $\mathrm{cm}$.

\section{STATISTICAL ANALYSES}

A sample size calculation performed using $\mathrm{G}^{*}$ Power $^{19}$ with an $\alpha=0.05$, and a power of 0.95 determined 70 participants were required to detect an effect size $f=0.15$, assuming an average correlation between repeated measures of $r=0.60$. Generalized estimating equations models were used for analysis to address the repeated measurements within participants, as well as the between-group differences. An exchangeable correlation matrix and log link function best fit the data. Robust estimators were computed. A sequential Bonferroni adjustment was used for follow-up comparisons. Participant age was tested as a covariate, and the use of glasses or contacts was tested as a fixed factor.

Reliability analyses were conducted to assess the level of agreement across measurements using a two-way randomeffects (consistency) model based on an average measurement. This method allowed bias assessment between mean measurement differences and estimation of an agreement interval, within which $95 \%$ of the differences between the two measurements fell. For the ICC estimates, reliability was evaluated as follows: values less than 0.50 were considered poor, $0.50-0.74$ were considered moderate, $0.75-0.90$ were considered good, and above 0.90 were considered excellent. ${ }^{20}$ Bland-Altman plots were also constructed based on mean differences. ${ }^{17}$ In Bland-Altman plots, the y-axis shows the difference between the two paired measurements $(\mathrm{A}-\mathrm{B})$, and the $\mathrm{X}$-axis is the average of these measures $([A+B] / 2)$. Bland and Altman recommended that $95 \%$ of the data points should lie within \pm 1.96 standard deviations (SD) of the mean difference. ${ }^{17}$ The average of paired differences is zero if no bias exists between measurements. All analyses were two-tailed, and the criterion level for significance was set a priori at $P<0.05$. Analyses were performed using SPSS ${ }^{\circledR}$ statistical software version 25 (IBM Corp., Armonk, NY). 
Table 3: Pairwise Comparisons of Near Point of Convergence (NPC) across the 4 Measured Test Targets by Distance $(\mathrm{N}=75)$

\begin{tabular}{|c|c|c|c|c|c|c|}
\hline \multirow{2}{*}{$\begin{array}{l}\text { NPC Test } \\
(\text { I })^{a}\end{array}$} & \multirow{2}{*}{$\begin{array}{l}\text { NPC Test } \\
(J)^{a}\end{array}$} & \multirow{2}{*}{$\begin{array}{c}\text { Mean } \\
\text { Difference (I-J) }\end{array}$} & \multirow{2}{*}{$\begin{array}{l}\text { Standard } \\
\text { Error }\end{array}$} & \multirow{2}{*}{$\begin{array}{c}\text { Bonferroni-Adjusted } P \\
\text { Value }\end{array}$} & \multicolumn{2}{|c|}{$95 \% \mathrm{Cl}$ for Difference } \\
\hline & & & & & $\begin{array}{l}\text { Lower } \\
\text { Limit }\end{array}$ & $\begin{array}{l}\text { Upper } \\
\text { Limit }\end{array}$ \\
\hline \multirow[t]{3}{*}{$\begin{array}{l}\text { Bernell } \\
\text { Vergel }\end{array}$} & $\begin{array}{l}\text { Tip of black } \\
\text { pen }\end{array}$ & -0.71 & 0.46 & 0.25 & -1.75 & 0.32 \\
\hline & $\begin{array}{l}\text { 12-Point } \\
\text { font }\end{array}$ & 1.33 & 0.32 & $<0.01$ & 0.53 & 2.13 \\
\hline & $\begin{array}{l}\text { 14-Point } \\
\text { font }\end{array}$ & 1.37 & 0.36 & $<0.01$ & 0.51 & 2.24 \\
\hline \multirow[t]{2}{*}{$\begin{array}{l}\text { Tip of black } \\
\text { pen }\end{array}$} & $\begin{array}{l}\text { 12-Point } \\
\text { font }\end{array}$ & 2.04 & 0.35 & $<0.01$ & 1.14 & 2.95 \\
\hline & $\begin{array}{l}\text { 14-Point } \\
\text { font }\end{array}$ & 2.09 & 0.35 & $<0.01$ & 1.16 & 3.01 \\
\hline $\begin{array}{l}\text { 12-Point } \\
\text { font }\end{array}$ & $\begin{array}{l}\text { 14-Point } \\
\text { font }\end{array}$ & 0.04 & 0.22 & 0.84 & -0.38 & 0.47 \\
\hline
\end{tabular}

a NPC results are reported in $\mathrm{cm}$.

Abbreviation: CI, confidence interval.

\section{RESULTS}

Seventy-five participants (59 females, 16 males) completed the study. Demographic characteristics are reported in Table 1. Twelve measurements of NPC were obtained for each participant. The mean (SD) of the 900 NPC measures was $7.11(3.67) \mathrm{cm}$. Age was inversely correlated with NPC $(p<0.01)$, so it was retained in the model. The use of glasses or contacts was not significant $(p=0.72)$ and was discarded from the model. Table 2 reports the mean and $95 \%$ confidence interval (CI) for the three trials of the four NPC measurement tools. Table 3 presents the Bonferroni-corrected results of pairwise comparisons across trials by measurement tool. The NPC for the tip of the black pen was not different from the Bernell Vergel 9-point font device $(p=0.25)$. The NPC for the 12-point and 14-point font targets were not different $(p=0.84)$, but both were smaller than the tip of the black pen and the Bernell Vergel 9-point font device $(P<0.01)$.

The ICCs of the four tests across the three trials were all excellent: 12-point font target (ICC $=0.96,95 \%$ $\mathrm{CI}=0.94-0.97)$; 14-point font target $\quad(\mathrm{ICC}=0.98$, 95\% $\mathrm{CI}=0.97-0.98$ ); tip of the black pen (ICC $=0.95$, 95\% $\mathrm{CI}=0.92-0.96)$; and the Bernell Vergel 9-point font device (ICC $=0.95$, 95\% CI=0.92-0.96).

The Bland-Altman plots for the pairwise measurements across all tests are presented in Figure 1. Pairing of the 12-point and 14-point font targets had the narrowest limits of agreement (Figure 1a), and pairing of the tip of the black pen and the Bernell Vergel 9-point font device had the widest (Figure 1f). The average of paired differences for the 12-point and 14-point font targets was zero (Figure 1a). Bias was limited in measurements across all tests, but 3 of the four measurements outside the limits of agreement for the 12-point and 14-point font targets pairing occurred at
Table 1: Demographic Characteristics of Participants $(\mathrm{N}=75)$ of the Current Study

\begin{tabular}{|c|c|}
\hline Demographic Characteristic & No. (\%) or Mean (SD) ${ }^{a}$ \\
\hline \multicolumn{2}{|l|}{ Sex } \\
\hline Male & $16(21.3)$ \\
\hline Female & $59(78.7)$ \\
\hline Age, y & $21.0(6.12)$ \\
\hline Glasses/contacts & $35(46.7)$ \\
\hline
\end{tabular}

a Age is reported as mean (SD).

Table 2: Mean (95\% Confidence Interval [CI]) of Near Point of Convergence (NPC) for the 3 Trials of the 4 Measured Tests $(\mathrm{N}=75)$

\begin{tabular}{ll}
\hline NPC Test & Mean $(95 \% \mathrm{Cl})$ \\
\hline 12-Point font target & $6.25(5.55-7.04)$ \\
14-Point font target & $6.21(5.57-6.92)$ \\
Tip of a black pen & $8.30(7.62-9.04)$ \\
Bernell Vergel device & $7.58(6.67-8.61)$ \\
\hline
\end{tabular}

a NPC results are reported in $\mathrm{cm}$.

mean NPC less than $5 \mathrm{~cm}$. For paired measurements, including the Bernell Vergel 9-point font device (Figures $\underline{1 \mathrm{~b}}$, $\underline{1 d}, \underline{1 f})$, extreme disagreements occurred at larger NPCs.

Sixty-one percent of all NPC measurements exceeded the conventional NPC threshold of $5 \mathrm{~cm}$ for concussion screening. The mean NPC measurement by target with a break- 


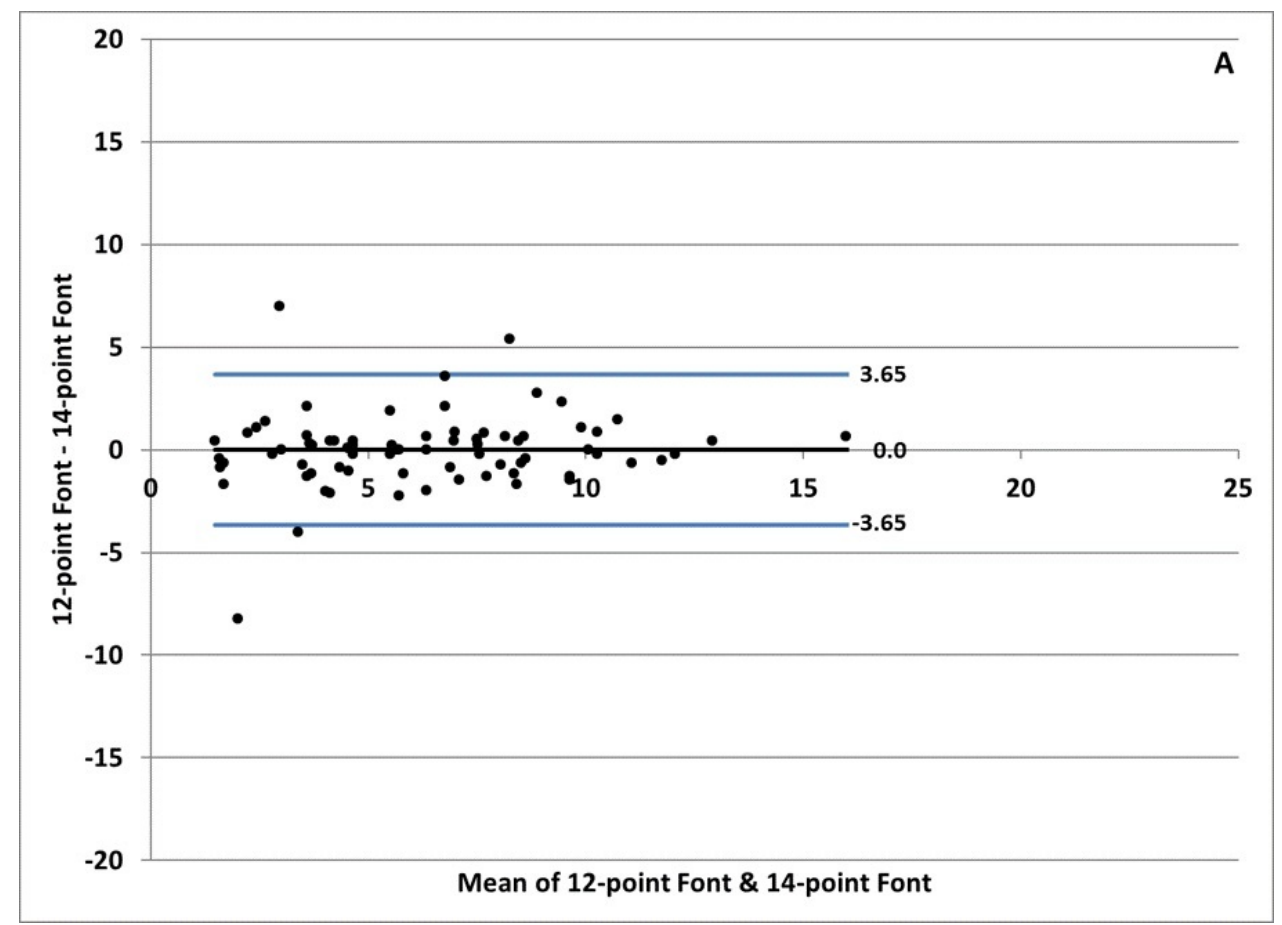

Figure 1a: Bland-Altman Charts for Pairwise Measurements of 12-Point Font and 14-Point Font. The blue lines represent upper and lower $95 \%$ limits of agreement. The black line represents the mean of differences between the two measurements.

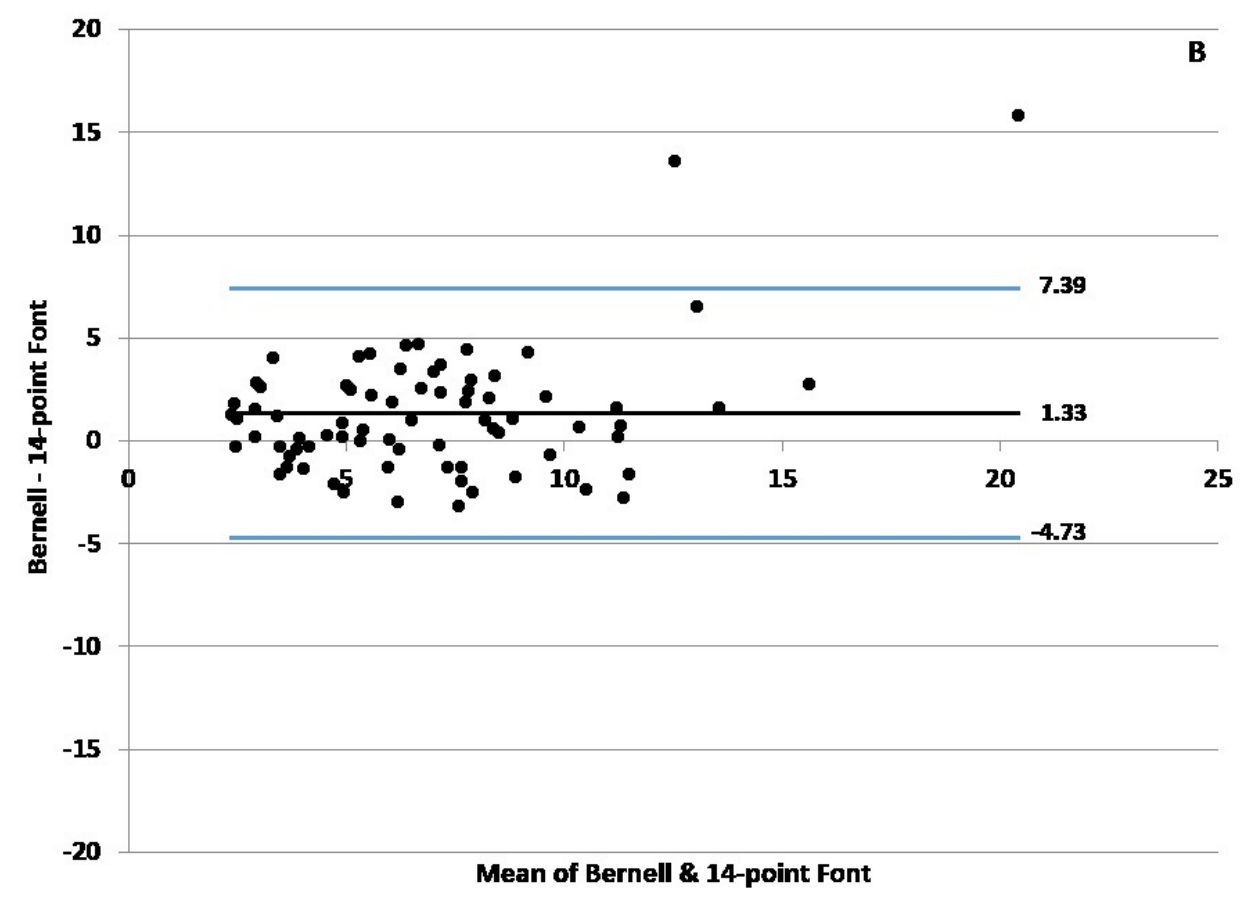

Figure 1b: Bland-Altman Charts for Pairwise Measurements of Bernell device and 14-Point Font. The blue lines represent upper and lower $95 \%$ limits of agreement. The black line represents the mean of differences between the two measurements. 


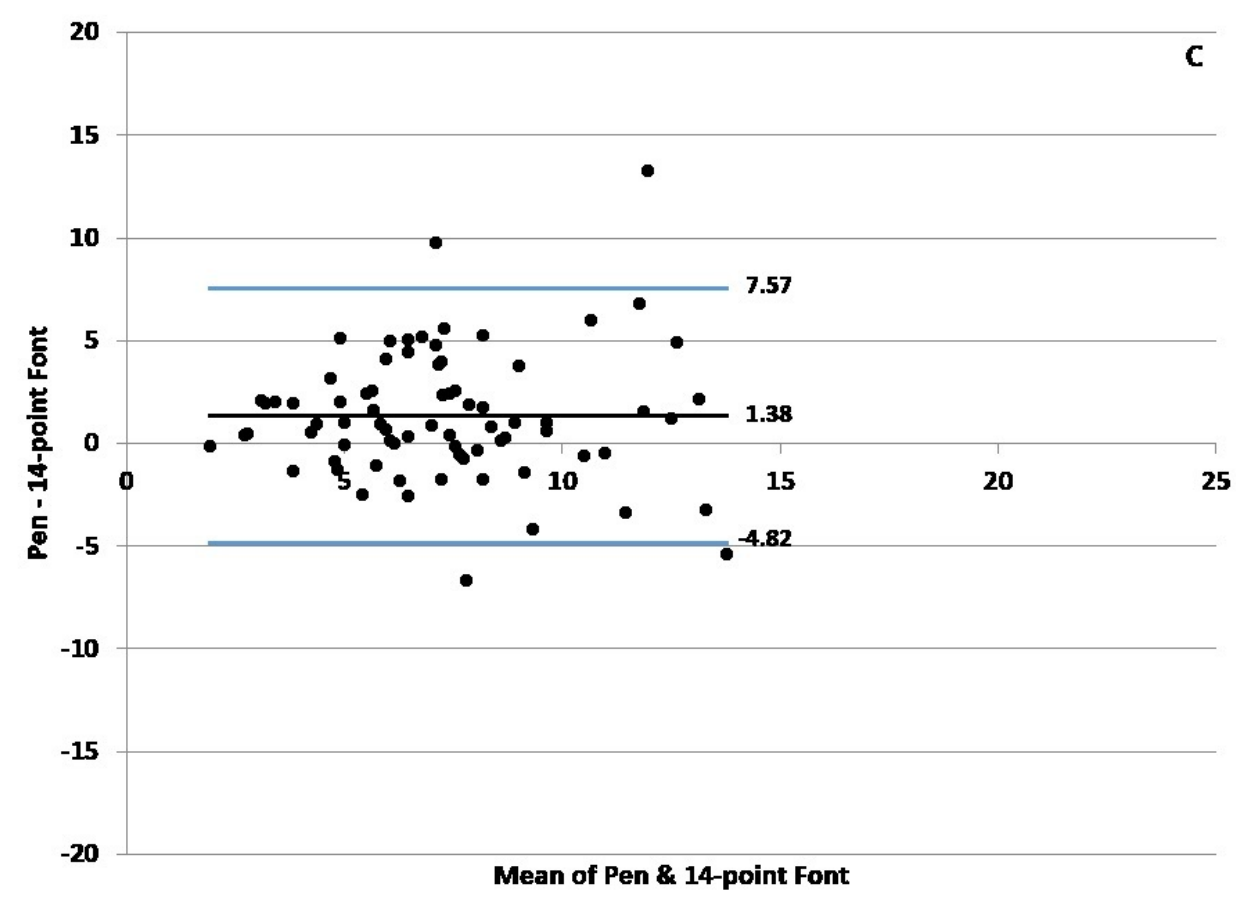

Figure 1c: Bland-Altman Charts for Pairwise Measurements of Pen and 14-Point Font. The blue lines represent upper and lower $95 \%$ limits of agreement. The black line represents the mean of differences between the two measurements.

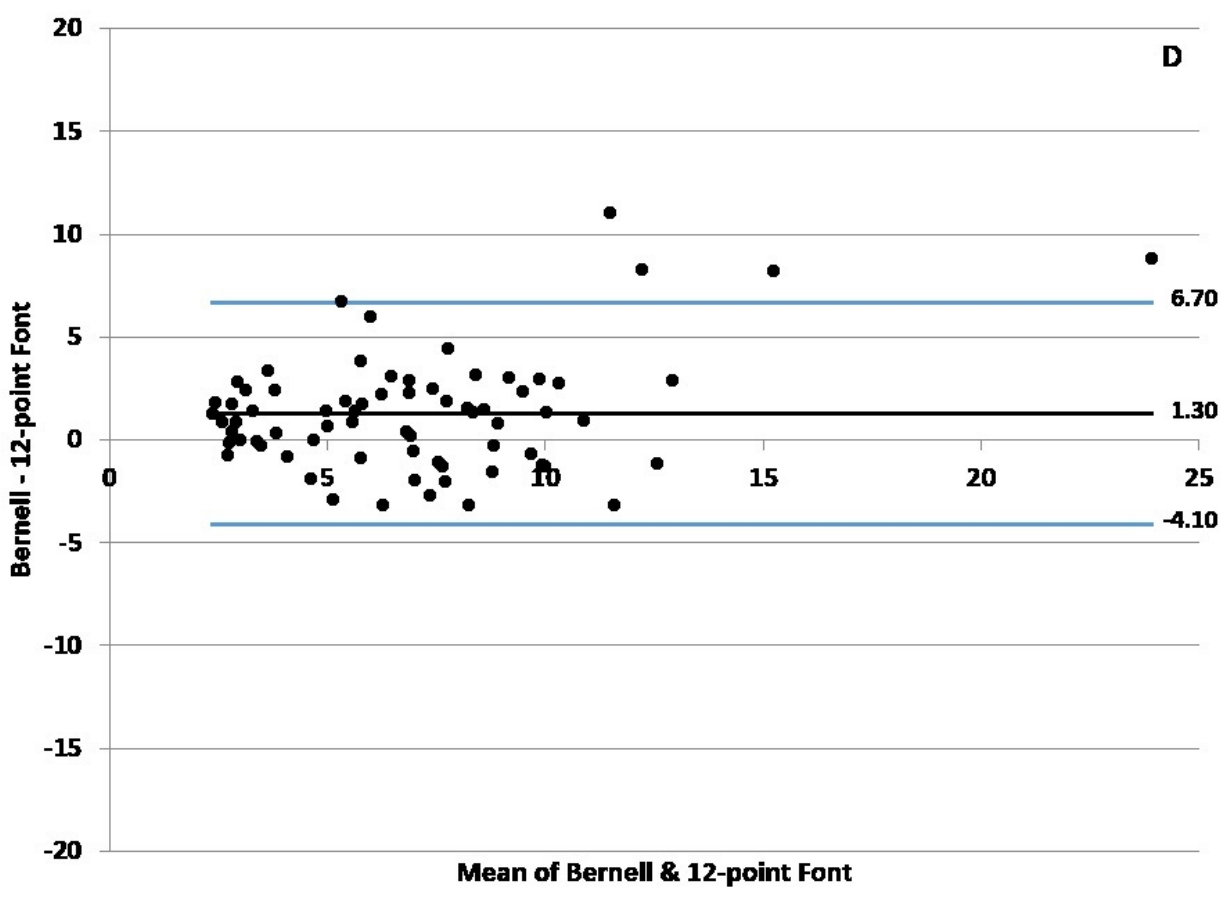

Figure 1d: Bland-Altman Charts for Pairwise Measurements of Bernell device and 12-Point Font. The blue lines represent upper and lower $95 \%$ limits of agreement. The black line represents the mean of differences between the two measurements.

\section{DISCUSSION}

The purpose of this study was to determine whether four different methods of measuring NPC yielded different estimates. These results suggest that NPC screening should be performed using a standardized approach, such as the 


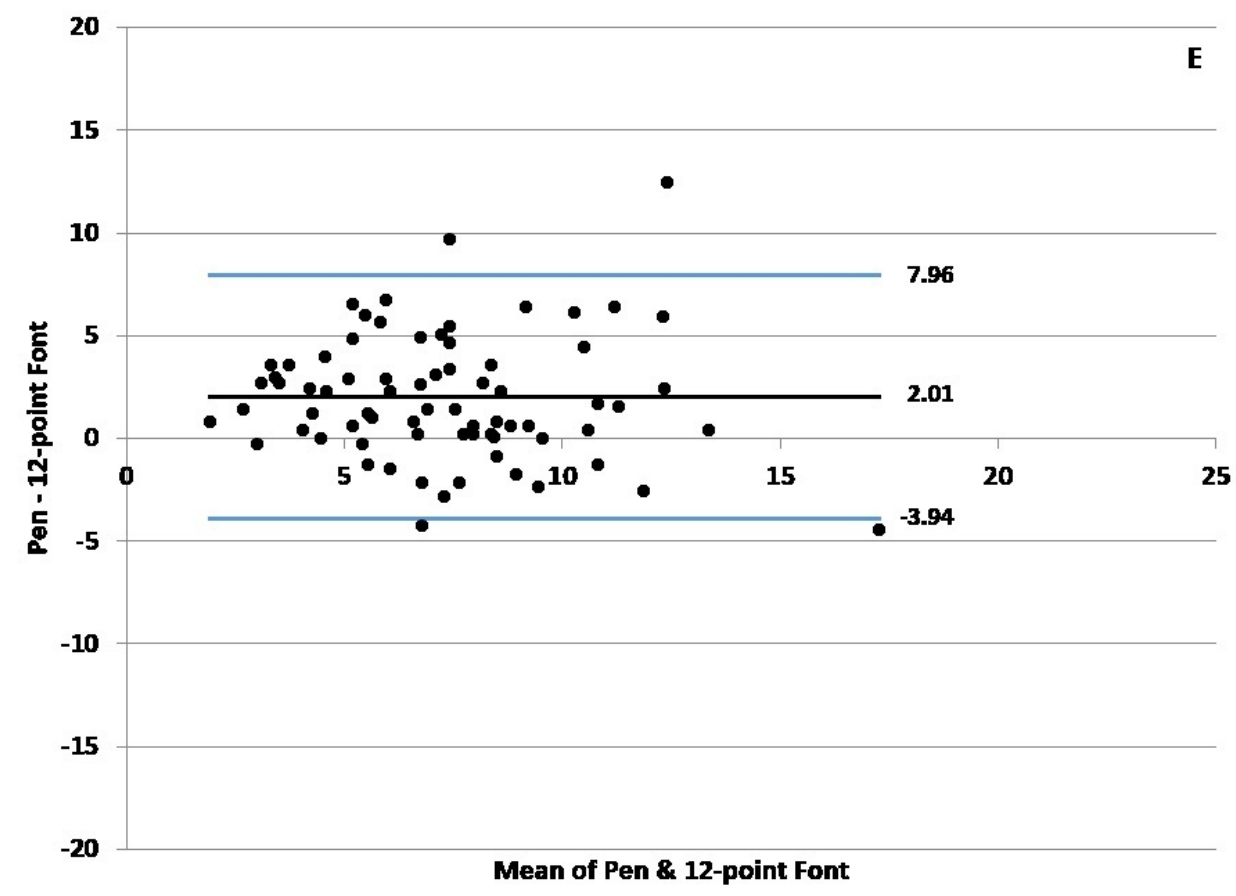

Figure 1e: Bland-Altman Charts for Pairwise Measurements of Pen and 12-Point Font. The blue lines represent upper and lower $95 \%$ limits of agreement. The black line represents the mean of differences between the two measurements.

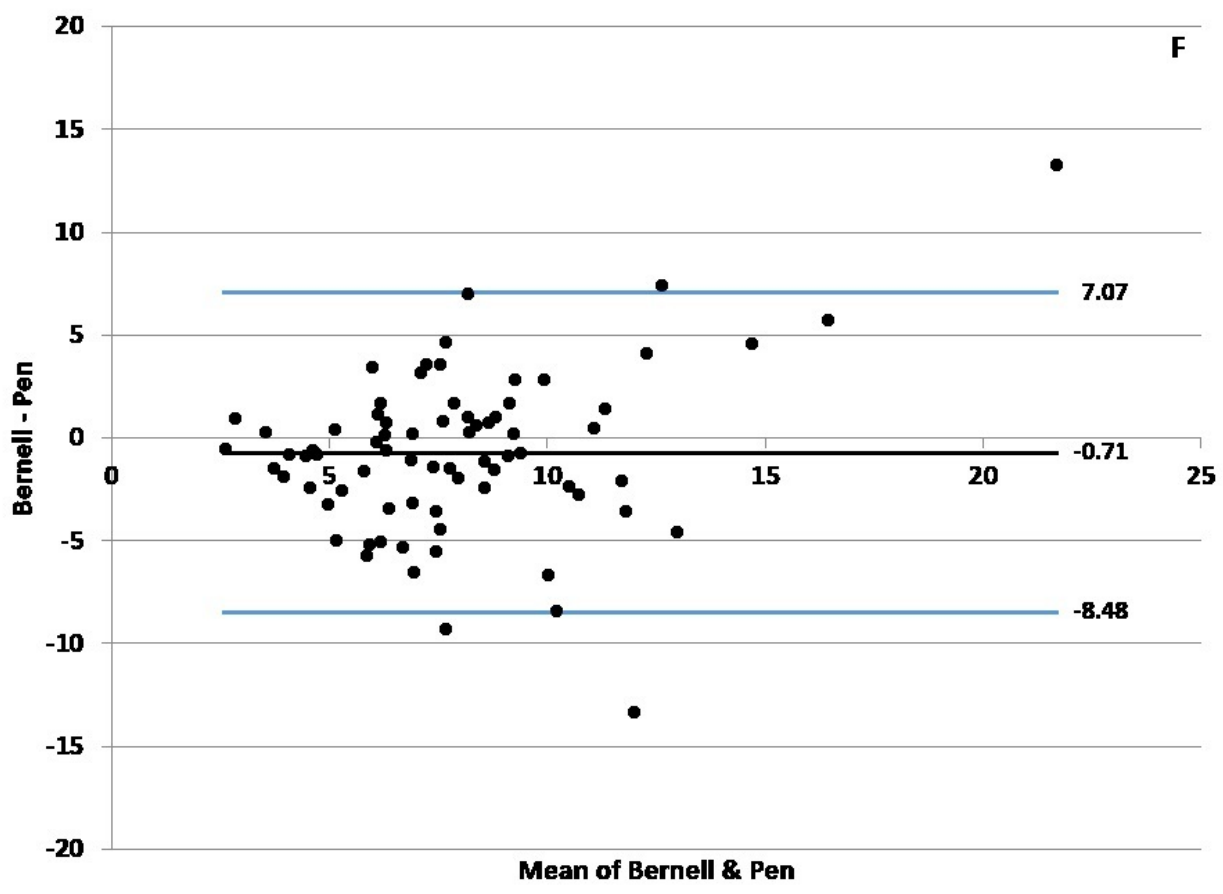

Figure 1f: Bland-Altman Charts for Pairwise Measurements of Bernell device and Pen. The blue lines represent upper and lower $95 \%$ limits of agreement. The black line represents the mean of differences between the two measurements.

VOMS because we found differences between the methods. The tip of the black pen and the Bernell Vergel 9-point font device, both small targets, had similar estimates of NPC.
The means of these two tests were $7.6 \mathrm{~cm}$ and $8.3 \mathrm{~cm}$, respectively, which is larger than the NPC threshold of $5 \mathrm{~cm}$ for identifying a concussion, based on the VOMS protocol. 
The mean NPCs for the 12-point and 14-point font targets were $6.3 \mathrm{~cm}$ and $6.2 \mathrm{~cm}$, respectively, and were not statistically different from each other, but they were significantly different from the other, smaller targets. These results were also larger than the NPC threshold for identifying a concussion; however, this threshold has not been endorsed by many disciplines. ${ }^{7,18,21-24}$

Evaluation of NPC in the clinical environment often uses items of convenience as targets, such as the tip of a pencil or pen, a penlight, or the tip of the index finger. ${ }^{23}$ Although convenient for screening, the items vary in size, and dexterity is required to maintain a standardized approach to assessment. ${ }^{21-23,25-27}$ These pragmatic measurements of NPC are used across disciplines. $7,13,22,23,28,29$ For example, Adler et al. ${ }^{18}$ investigated convenient tools that are used in an optometry clinic, such as the tip of the pen, fingertip, penlight, and two targets suspended on a ruler that were not 12-or 14-point font size in a population of children. In the current study, targets were similar in clinical usefulness but were centered around investigating the size of the target being moved towards the participant.

Setting a threshold for abnormal NPC can be challenging. For instance, research suggests that approximately $5 \%$ of healthy, non-concussed adults routinely have an abnormal NPC. ${ }^{13,22}$ Some have suggested that the prevalence of abnormal NPC ranges from $1 \%$ to $33 \%$ in healthy individuals. $^{22}$ Optometrists suggest that normal NPC is between $8 \mathrm{~cm}$ and $10 \mathrm{~cm}$, which calls into question the $5-\mathrm{cm} \mathrm{NPC}$ threshold used in the VOMS. ${ }^{18,24}$ This variability in thresholds has led some to recommend baseline testing of the NPC. ${ }^{30}$ A baseline measurement at the beginning of a season could be used as a comparison for athletes with a suspected concussion. Moran et al. ${ }^{30}$ suggested that individualized baseline testing could reduce the likelihood of false-positive assessments after a concussion. In the current study, using the standard $5 \mathrm{~cm}$ NPC threshold resulted in $61.3 \%$ of participants receiving an abnormal NPC. If the threshold for an abnormal NPC were set at $10 \mathrm{~cm}$ for healthy, non-concussed individuals, then $32 \%$ of the participants would be classified as abnormal. Thus, if the NPC were not tested at baseline, a large percentage of healthy participants in this study would be incorrectly classified as abnormal. Considering the time required for the sports professional to assess NPC at baseline, the Bernell Vergel may be the most efficient screening tool for preseason baseline measurement. Given these results, a baseline screening is recommended to identify athletes with large NPCs so they are not incorrectly classified as abnormal based on their NPC score.

Although convergence insufficiency has been defined as an abnormal NPC, ${ }^{13,29}$ optometrists and ophthalmologists disagree with this suggestion. ${ }^{18,21,23,24,31}$ Instead, convergence insufficiency should include multiple types of tests and multiple measures to identify NPC. Ophthalmologists perform comprehensive exams that use NPC as one of the measures for assessing convergence insufficiency. In a recent study, Stiebel-Kalish et al. ${ }^{23}$ used ocular alignment with distance and near cover testing, Maddox distance heterophoria testing with a Maddox rod, Maddox-Thorington near heterophoria testing with a Thorington card, Randot stereopsis with booklet testing, NPC with a target-specific to the patient's vision, the amplitude of accommodation with an acuity target, and fusional vergence with targets and prisms. However, these optometric tests should only be performed by ophthalmologists or optometrists who are trained to administer them. Further, other disciplines should not suggest that convergence insufficiency is only identified by a reduced NPC and should not use the term convergence insufficiency even if these disciplines are only screening for NPC. Others should instead refer to a reduced NPC result as an abnormal NPC to decrease confusion across disciplines.

Results of the current study highlight the importance of standardizing NPC screening. The larger targets tended to have higher ICC values across the three trials and narrower limits of agreement. If NPC is used in a serial fashion, for example at baseline and periodically thereafter or as an assessment of progress during rehabilitation from a concussion, it is crucial that the same size target be used. Otherwise, differences in estimated NPC due to measurement variability will obscure any real changes that may be occurring.

The current study had several limitations. For instance, a convenience sample of participants recruited from a local university was used, so results should be generalized with caution. Another limitation is that the details of the participants' visual history were not obtained. As such, visual dysfunctions, such as stigmatisms or other visual disorders, may have influenced performance on the NPC tests. Participants were asked if they wore glasses or contacts but were not screened for behavioral/psychological disorders such as ADHD or dyslexia that may have affected their test results. Future studies should include a visual history to determine whether this plays a role in NPC.

\section{CONCLUSION}

The VOMS, which uses a 14-point font size target for concussion screening, is standardized and practical. Assessment of NPC should be standardized across all disciplines with respect to the target, the speed of the target being moved toward the athlete, and the NPC cut-off score for what is considered abnormal. Results of the current study support previous research that indicates the size of the target used to measure NPC should be consistent across measurements. The authors also recommend that NPC measurements should be conducted pre-season to establish an NPC baseline as a potential comparison if the athlete sustains a concussion.

\section{CONFLICTS OF INTEREST}

The authors do not have any conflict of interest.

Submitted: March 02, 2020 CDT, Accepted: October 10, 2020 CDT 
This is an open-access article distributed under the terms of the Creative Commons Attribution 4.0 International License (CCBY-NC-SA-4.0). View this license's legal deed at https://creativecommons.org/licenses/by-nc-sa/4.0 and legal code at https://creativecommons.org/licenses/by-nc-sa/4.0/legalcode for more information. 


\section{REFERENCES}

1. Langlois JA, Rutland-Brown W, Wald MM. The epidemiology and impact of traumatic brain injury: a brief overview. J Head Trauma Rehabil.

2006;21(5):375-378.

2. Dompier TP, Kerr ZY, Marshall SW, et al. Incidence of concussion during practice and games in youth, high school, and collegiate american football players. JAMA Pediatr. 2015;169(7):659-665. doi:10.1001/jama pediatrics.2015.0210

3. Heitger MH, Anderson TJ, Jones RD, DalrympleAlford JC, Frampton CM, Ardagh MW. Eye movement and visuomotor arm movement deficits following mild closed head injury. Brain. 2004;127(3):575-590. doi:10.1093/brain/awh066

4. Ventura RE, Balcer LJ, Galetta SL. The neuroophthalmology of head trauma. Lancet Neurol. 2014;13(10):1006-1016. doi:10.1016/S1474-4422(14)7 $\underline{0111-5}$

5. Ventura RE, Jancuska JM, Balcer LJ, Galetta SL. Diagnostic tests for concussion: is vision part of the puzzle? J Neuroophthalmol. 2015;35(1):73-81. doi:10.1 097/WNO.0000000000000223

6. Heitger MH, Jones RD, Macleod AD, Snell DL, Frampton CM, Anderson TJ. Impaired eye movements in post-concussion syndrome indicate suboptimal brain function beyond the influence of depression, malingering or intellectual ability. Brain. 2009;132(Pt 10):2850-2870. doi:10.1093/brain/awp181

7. Mucha A, Collins MW, Elbin RJ, et al. A brief vestibular/ocular motor screening (VOMS) assessment to evaluate concussions: preliminary findings. Am J Sports Med. 2014;42(10):2479-2486. do i:10.1177/0363546514543775

8. Kontos AP, Elbin RJ, Schatz P, et al. A revised factor structure for the post-concussion symptom scale: baseline and postconcussion factors. Am J Sports Med. 2012;40(10):2375-2384. doi:10.1177/03635465124554 $\underline{00}$

9. Alvarez TL, Kim EH, Vicci VR, Dhar SK, Biswal BB, Barrett AM. Concurrent vision dysfunctions in convergence insufficiency with traumatic brain injury. Optom Vis Sci. 2012;89(12):1740-1751. doi:10.1097/O PX.0b013e3182772dce
10. Brahm KD, Wilgenburg HM, Kirby J, Ingalla S, Chang CY, Goodrich GL. Visual impairment and dysfunction in combat-injured servicemembers with traumatic brain injury. Optom Vis Sci. 2009;86(7):817-825. doi:10.1097/OPX.0b013e3181adf $\underline{\mathrm{f} 2 \mathrm{~d}}$

11. Ciuffreda KJ, Kapoor N, Rutner D, Suchoff IB, Han ME, Craig S. Occurrence of oculomotor dysfunctions in acquired brain injury: a retrospective analysis. Optometry. 2007;78(4):155-161. doi:10.1016/j.optm.2 006.11 .011

12. Cohen M, Groswasser Z, Barchadski R, Appel A. Convergence insufficiency in brain-injured patients. Brain Inj. 1989;3(2):187-191.

13. Pearce KL, Sufrinko A, Lau BC, Henry L, Collins MW, Kontos AP. Near point of convergence after a sport-related concussion: measurement reliability and relationship to neurocognitive impairment and symptoms. Am J Sports Med. 2015;43(12):3055-3061. doi:10.1177/0363546515606430

14. Truong JQ, Ciuffreda KJ. Quantifying pupillary asymmetry through objective binocular pupillometry in the normal and mild traumatic brain injury (mTBI) populations. Brain Inj. 2016;30(11):1372-1377. doi:1 $\underline{0.1080 / 02699052.2016 .1192220}$

15. Anzalone AJ, Blueitt D, Case T, et al. A positive vestibular/ocular motor screening (VOMS) is associated with increased recovery time after sportsrelated concussion in youth and adolescent athletes. Am J Sports Med. 2017;45(2):474-479. doi:10.1177/036 $\underline{3546516668624}$

16. Alsalaheen BA, Mucha A, Morris LO, et al. Vestibular rehabilitation for dizziness and balance disorders after concussion. J Neurol Phys Ther. 2010;34(2):87-93. doi:10.1097/npt.0b013e3181dde568

17. Bland JM, Altman DG. Measuring agreement in method comparison studies. Stat Methods Med Res. 1999;8(2):135-160. doi:10.1177/096228029900800204

18. Adler PM, Cregg M, Viollier AJ, Margaret Woodhouse J. Influence of target type and RAF rule on the measurement of near point of convergence. Ophthalmic Physiol Opt. 2007;27(1):22-30. doi:10.111 1/j.1475-1313.2006.00418.x

19. Faul F, Erdfelder E, Lang AG, Buchner A. G*Power 3: A flexible statistical power analysis program for the social, behavioral, and biomedical sciences. Behavior Research Methods. 2007;39:175-191. 
20. Portney LG, Watkins MP. Foundations of Clinical Research: Applications to Practice. 3rd ed.

Philadelphia, PA: F. A. Davis Company; 2015.

21. Menjivar AM, Kulp MT, Mitchell GL, Toole AJ, Reuter K. Screening for convergence insufficiency in school-age children. Clin Exp Optom. 2018;101(4):578-584. doi:10.1111/cxo.12661

22. Scheiman M, Gallaway M, Frantz KA, et al. Nearpoint of convergence: test procedure, target selection, and normative data. Optom Vis Sci. 2003;80(3):214-225.

23. Stiebel-Kalish H, Amitai A, Mimouni M, et al. The discrepancy between subjective and objective measures of convergence insufficiency in whiplashassociated disorder versus control participants. Ophthalmology. 2018;125(6):924-928. doi:10.1016/j.o phtha.2017.11.030

24. Ostadimoghaddam $\mathrm{H}$, Hashemi $\mathrm{H}$, Nabovati $\mathrm{P}$, Yekta A, Khabazkhoob M. The distribution of near point of convergence and its association with age, gender and refractive error: a population-based study. Clin Exp Optom. 2017;100(3):255-259. doi:10.1111/cx $\underline{0.12471}$

25. Hayes GJ, Cohen BE, Rouse MW, De Land PN. Normative values for the nearpoint of convergence of elementary schoolchildren. Optom Vis Sci. 1998;75(7):506-512.
26. Giffard P, Daly L, Treleaven J. Influence of neck torsion on near point convergence in subjects with idiopathic neck pain. Musculoskelet Sci Pract. 2017;32:51-56. doi:10.1016/j.msksp.2017.08.010

27. Scheiman M, Mitchell GL, Cotter S, et al. A randomized clinical trial of vision therapy/orthoptics versus pencil pushups for the treatment of convergence insufficiency in young adults. Optom Vis Sci. $2005 ; 82(7): 583-595$.

28. Kawata K, Rubin LH, Lee JH, et al. Association of football subconcussive head impacts with ocular near point of convergence. JAMA Ophthalmol. 2016;134(7):763-769. doi:10.1001/jamaophthalmol.20 $\underline{16.1085}$

29. Kawata K, Tierney R, Phillips J, Jeka JJ. Effect of repetitive sub-concussive head impacts on ocular near point of convergence. Int J Sports Med. 2016;37(5):405-410. doi:10.1055/s-0035-1569290

30. Moran RN, Covassin T, Elbin RJ, Gould D, Nogle S. Reliability and normative reference values for the vestibular/ocular motor screening (VOMS) tool in youth athletes. Am J Sports Med. 2018;46(6):1475-1480. doi:10.1177/036354651875697 9

31. Omar R, Kuan YM, Zuhairi NA, Manan FA, Knight VF. Visual efficiency among teenaged athletes and non-athletes. Int J Ophthalmol. 2017;10(9):1460-1464. doi:10.18240/ijo.2017.09.20 